\title{
Foot Care Knowledge Assessment among Type 2 Diabetic Patients attending Three Family Medicine Centers in Cairo
}

\author{
Diaa Marzouk ${ }^{1}$, Rana A El-Hilaly ${ }^{2}$, Dalia G Sos ${ }^{3}$, Nouran Fakkar ${ }^{4}$ \\ ${ }^{1}$ Public Health and Head of Family Medicine Department, ${ }^{2}$ Physical Medicine, ${ }^{3}$ Pubic Health \\ Department, ${ }^{4}$ Family Medicine, Faculty of Medicine, Ain Shams University
}

Received: February $2016 \quad$ Accepted :May 2016

\begin{abstract}
Background: Diabetic complications are strongly attributed to poor foot care knowledge and practice. Knowledge about diabetes enables patients to play an active role in effective diabetes self-management. Proper daily foot care is an effective part of diabetic foot ulcer (DFU) prevention and enables diabetic patients to early detect foot abnormalities and injuries, thus reduce or even prevent the risk of foot ulceration. Objectives: to measure foot care knowledge and to identify possible associated factors among Egyptian diabetic patients attending three Family Medicine centers in Cairo Methods: A cross-sectional study was carried out in three Family Medicine centers on 140 diabetic who met the inclusion criteria. Data on foot care knowledge was collected using a structured interview questionnaire. Results: More than half $(62.1 \%)$ of the participants had poor foot care knowledge, $24.3 \%$ had satisfactory level and only $13.6 \%$ have good knowledge. The mean of knowledge score was as follow in the three centers; El Sadis (7.18 \pm 2.697$)$ El Darrasa (6.92 \pm 3.168$)$ and in Saraya was (5.96 \pm 3.037$)$ and no statistical difference in foot care knowledge score or grade was found between the three centers. A strong and significant relation was found between income and knowledge grade. Also Longer disease duration and history of foot ulcer were associated with good foot care knowledge. Conclusion: Poor foot care knowledge was evident among the study participants in the three Family Medicine Centers and hence interactive health educational programs targeting type 2 diabetic patients are strongly recommended.
\end{abstract}

Key words: Diabetes Type 2- Diabetic foot complications - Health education - Foot care knowledge. Corresponding author: Prof. Diaa Marzouk. E-mail: diaamarzouk@yahoo.com

\section{Introduction}

According to the International Diabetes Federation (IDF) data, Egypt is among the world's top 10 countries in number of people with diabetes ${ }^{1}$ and according to the WHO stepwise survey in Egypt in 2011, the prevalence of Diabetes Mellitus is $17 \%$ of total Egyptian population. ${ }^{2}$ This high prevalence of DM is associated with increase in its complications among diabetic patients. Diabetic foot problems as one important complication of DM constitute an increasing public health problem and are a leading cause of hospital admission, amputation and mortality in diabetic patients. $^{3} \quad$ Worldwide, approximately $40-60 \%$ of all non-traumatic amputations of the lower extremities are performed in patients with diabetes. ${ }^{4}$

Education is the key element in successful management of diabetes, as knowledge about diabetes enables patients to play an active role in effective diabetes selfmanagement. Patient education is a powerful weapon to overcome behavioral 
and psychological barriers and improve self-management skills. ${ }^{5}$

Proper daily foot care is an essential low cost and effective part of diabetic foot ulcer (DFU) prevention. Performing daily foot care routines enables diabetic patients to detect foot abnormalities and injuries earlier, hence reduce or even prevent the risk of foot ulceration effectively ${ }^{(6)}$. As an example for proper foot care the patient should be taught to care for his feet by washing them daily, drying them carefully particularly between the toes. ${ }^{7}$

Several studies have been conducted to assess knowledge among diabetics and factors affecting it. In Southern India, a study conducted in secondary rural hospital has found that male gender, poor education status, and recently diagnosed with diabetes are significantly associated with poor foot care knowledge ${ }^{(8) .}$ Another study done in Pakistan among diabetic patients attending outpatient clinic of Jinnah Hospital in Lahore reported that $29.3 \%$ of the diabetics have good knowledge, $40 \%$ have satisfactory knowledge and $30.7 \%$ have poor knowledge about foot care. ${ }^{9}$

In Egypt, a study was done in the outpatient diabetes clinic at Mansoura University Specialized Medical Hospital on 1220 diabetic patients found that $93 \%$ of them received no prior foot education. ${ }^{10}$

Aim: To measure foot care knowledge and to identify possible associated factors among the Egyptian diabetic patients attending three Family Medicine centers in Cairo.

\section{Participants \& Methods:}

A Descriptive cross-sectional study was carried out at Family medicine clinics in three Family Medicine centers in Cairo which are; El-Darrasa, Saraya El- Kobba and El- Sadis Family Medicine centers. They are located in Wasat El Kahira, El
Zayton and Nasr City districts in Cairo respectively, each center receives about 50 diabetic patients per month. The three Centers were pooled in one group because of the small sample. 140 diabetic patients were recruited from March till June 2016 based on the following Inclusion criteria: Known cases of type 2 Diabetes Mellitus aging between 30 and 70 years old. Exclusion criteria: Patients with toes or foot amputation, Patient shaving active foot ulcers and Patients with visual or cognitive impairment. Sample size was calculated based on a prevalence of foot care knowledge of about $32 \%{ }^{(8)}$ at $95 \%$ confidence level, width of confidence interval of 0.15 and alpha error of 0.025 . Data was collected using interviewed questionnaire which was adopted from the study done by Thunberg and Hellenberg. ${ }^{11}$ Reliability of the questionnaire was measured by Cronbach's alpha coefficient and was found to be 0.75 and was adjusted to the local socio-cultural context.

The questionnaire included the following items: Socio -demographic data (age, gender, education, occupation, income, etc.).Medical history (duration of diabetes, family history, mode of treatment, diabetic complications as history of DFU and symptoms of peripheral neuropathy) Questions about knowledge: It consists of fifteen true or false questions regarding foot care knowledge. The "True" answer of all questions is the right answer. Each correct answer was given one mark of total 15 marks. If the score is more than $70 \%$ (11-15) it was considered good knowledge. If the score is $50-70 \%(10-8)$ it was considered satisfactory knowledge, and poor knowledge if the score was less than $50 \%(<8){ }^{(12)}$. Patients were asked if they know the necessity of the following: (a) Controlling their blood glucose in order to prevent the complications of Diabetes. (b)
No. 3

July

2017 
Washing the feet by warm water and inspecting them daily. (c) Drying the feet after washing and keeping them soft by using moisturizers. (d) Trimming nails straight with care. (e) Wearing comfortable shoes and not walking barefoot. (f) Being aware of the warning signs that need medical consultation. Questions about foot care education: Patients were asked about the following: If they attended any foot care education classes before, read any handouts on foot care before and the most effective way for increasing foot care knowledge from their point of view. Data was processed and analyzed using SPSS (Statistical Package for Social Science) software version 20.0.

\section{Ethical Consideration:}

Administrative approval from Ministry of Health (MOH) and Faculty of Medicine, Ain Shams University Ethical committee board approval were obtained to carry out the study in three Family Medicine Centers. Informed consents were taken from all the participants.

\section{Results:}

I- Description of socio-demographic and medical data among the study population: Out of 140 participants, 114 $(81.4 \%)$ were females and $81 \%$ were above the age of 50 years. About (64.3\%) of the study population were married, housewives represent $(72.9 \%)$ of them. Minority were highly educated (college) and the majority were illiterate $(50.7 \%)$. And nearly half $(43.6 \%)$ of the studied population reported inadequate income with a median of 650 L.E/month (Table 1). As for medical data: The duration of diabetes was less than 10 years in $55.7 \%$ of them and More than two third $(75.7 \%)$ of the studied population had positive family history of diabetes. Most of the studied participants $(86.4 \%)$ were receiving oral hypoglycemic drugs as treatment yet $66.9 \%$ ) of the studied population did not follow up their treatment with their doctor regularly. On asking about current foot problem; Majority of the studied population $(75.7 \%)$ reported having feet numbness, tingling, pins or itching sensation. Minority of them (3.6\%) reported having current foot sore or blister and $(9.3 \%)$ had calluses.

II- Distribution of foot care knowledge score among the studied population: More than half $(62.1 \%)$ of the participants had poor foot care knowledge, $24.3 \%$ had satisfactory level and only $16.3 \%$ have good knowledge as shown in (Table 1). The mean of knowledge score was as follows in the three centers; El Sadis (7.18 \pm 2.697$)$ El Darrasa (6.92 \pm 3.168$)$ and in Saraya was $(5.96 \pm 3.037)$ as shown in (Table 2) and no statistical difference in foot care knowledge score or grade was found between the three centers. Nearly all the studied population $(90.7 \%)$ knew the importance of taking the treatment to avoid complications and (95\%) of them were aware of the importance of washing their feet daily. About half of them (50\%) quietly understand that they should use warm water for washing or bathing, and that they should check the temperature of water before using (52.9\%). About $42.9 \%$ of them know that they should dry the feet after washing .More than half of them $(58.6 \%)$ know that they should check the shoes from inside before wearing, and $(51.4 \%)$ of them know that they should not walk bare feet and $(57.1 \%)$ of them know the warning signs for which medical consultation is required (Table 3 ).

III- Foot care knowledge and related factors: A highly significant relation was found between income and knowledge grade, where low income was associated with poor knowledge and higher income 
was associated with satisfactory and good knowledge (Table 4). Also Longer disease duration (11 years) (Table 5), history of foot ulcer were associated with good foot care knowledge. However, no significant relation was found between knowledge grade and other socio-demographic characteristics as gender, education and occupation (Table 6).

IV- Foot care education: A minority of the studied population (7.9\%) attended a class for foot care education. Only (2.9\%) read handouts on foot care despite that most of them $(91.4 \%)$ like to have one. On the other side, most of them $(73.6 \%)$ thought that individual health education is the most effective way for increasing foot care knowledge and practice, while $(15.7 \%)$ of them preferred media as Television and Internet (Table 7).

\section{Discussion:}

A total number of 140 participants were recruited in this study, mostly females $(81.4 \%)$ and this could be related to the time of clinics which was in the morning when most of males are busy with their work. Moreover, Good ridge et al. ${ }^{13}$ found that females were more active in their selfcare while males sought medical advice more for acute problems, this explains why there were more females visiting the Family Medicine clinics. El- Darrasa Center population had higher percentage of illiteracy and about quarter of them worked as laborers. While, El-Sadis Center's population worked as Government officers $(17.5 \%)$ and more than third of them had enough income compared to half of Saraya El- Kobba and El- Darrasa Centers' population who had totally inadequate income. This may be due to the catchment area of Centers. Although the residents of Nasr city have higher social class than Saraya El Kobba and El Darrasa, their knowledge of foot care was poor. Majority of the study subjects $(84.4 \%)$ were receiving oral hypoglycemic drugs as treatment, this agrees with the study done in India by George et al. ${ }^{8}$ where $81.6 \%$ were on oral treatment. But, most of the study subjects did not follow up their treatment with their doctor regularly. This could be explained by the fact that most of patients who visit the Family Medicine Centers receive oral treatment as it is one of the drugs available there free of cost. While routine investigations of diabetes are not available in most of Centers, so the patients should be referred to a secondary care hospital which was not done in most of cases, as referral system is not well established in the Egyptian health care system. Regarding foot care knowledge among the study subjects, more than half $(62.1 \%)$ of them had poor foot care knowledge. While satisfactory knowledge was $24.3 \%$ and good knowledge was $13.6 \%$. So, satisfactory and good knowledge collectively were $37.9 \%$ similar to George et al. ${ }^{8}$ and Viswanathan et al. ${ }^{14}$ who reported $32 \%$ knowledge prevalence. Yet it is considered a poor knowledge score compared to that of the study done by Thunberg and Hellenberg ${ }^{11}$ where $74 \%$ of the studied population had good knowledge. The study showed that nearly all the studied population $(90.7 \%)$ knew the importance of taking the treatment to avoid complications and (95\%) of them were aware of the importance of washing their feet daily. This goes in agreement with DESALU et al. ${ }^{15}$ who found that $94.3 \%$ of the participants knew the importance of taking the treatment to avoid complications and the importance of washing their feet daily. Concerning knowledge and its related factors, the study showed that subjects with higher income had good 
knowledge. Most of them reported using media e.g. TV and Internet as a main source for gaining knowledge about their disease. This agrees with Thunberg and Hellenberg ${ }^{11}$ who found that participants who had good knowledge while had not attended foot care classes, gained knowledge by themselves through media. Concerning knowledge and its related factors, the study showed that subjects with higher income had good knowledge. Most of them reported using media e.g. TV and Internet as a main source for gaining knowledge about their disease. This agrees with Thunberg and Hellenberg ${ }^{11}$ who found that participants who had good knowledge yet, did not attend foot care classes, they gained knowledge by themselves through media.

\section{Conclusion \& Recommendation:}

Poor foot care knowledge was evident among the study participants in the three Family Medicine Centers. Most of the patients did not attend foot care education classes or read any foot care handouts before. Yet, they expressed their willingness to enhance their knowledge through handouts about foot care or through individual health education in clinics, hence we recommend the following: Heath education programs targeting type 2 diabetes should take priority at the level of the secondary prevention to limit the complications and hence better quality of life among them. The health education should cover foot care knowledge, beneficial foot care practices, treatment compliance and follow up. Printed illustrative handouts and brochures should be routinely distributed in Family Medicine Centers' clinics to the diabetics as a preliminary step to improve their knowledge.
Enhance the awareness and the importance of Podiatry care and the necessity to be incorporated in the Egyptian health care system. And that diabetic patient should have regular scheduled visits to podiatrists. Family Medicine physicians should make sure that patients do routine diabetes investigations. This prevents many diabetic complications that occur in uncontrolled patients.

\section{References:}

1. International Diabetes Federation. (ADA) (2013).Diabetes Atlas.6th ed.: International Diabetes Federation.

2. World Health Organization (WHO) (2011). Stepwise survey in Egypt. Last Accessed Jan 2016. Available From: http://www.emro.who.int/egy/programmes/n oncommunicable-diseases.html

3. Ogbera AO, Fasanmade O, Ohwovoriole AE, Adediran O. (2006). An assessment of the disease burden of foot ulcers in patients with diabetes mellitus attending a teaching hospital in Lagos, Nigeria.Int J Low Extrem Wounds; 5: 244 -249 .

4. Apelgvist $\mathbf{J}$ and Larsson J. (2000). What is the most effective way to reduce incidence of amputation in the diabetic foot? Diabetes Metab Res; 16(1):S75-83

5. Tessier DM and Vague L. (2007). Diabetes and Education in the elderly. Diabetes and Metabolism. 2007; 33:575-85.

6. Hokkam EN. (2009). Assessment of risk factors in diabetic foot ulceration and their impact on the outcome of the disease. Primary Care Diabet; 3:219-24.

7. American Diabetes Association (ADA) [Internet] (2014). Diabetes foot care guidelines. Last accessed June 2016. Available from: http://www.diabetes.org/ living-with-diabetes/complications/footcomplications/foot-care.html. 
8. George H, Rakesh PS, Krishna M, Alex R, Abraham VJ, George K, Prasad JH. (2013). Foot Care Knowledge and Practices and the Prevalence of Peripheral Neuropathy Among People with Diabetes Attending a Secondary Care Rural Hospital in Southern India . J Fam Med and Primary Care; 2(1):27-32

9. Hasnain S, Sheikh NH. (2009). Knowledge and practices regarding foot care in diabetic patients visiting diabetic clinic in Jinnah Hospital, Lahore .J Pak Med Assoc; 59(10): 687-690.

10. El-Nahas MR, Gawish NMS, Tarshoby MM, State OL, Boulton AJM. (2008): The prevalence of risk factors for foot ulcer in diabetic patients. Pract Diab Int; 25(9): 362-66.

11. Thunberg S, Hellenberg S. (2013). Knowledge and practices regarding foot care among patients with Type 2 Diabetes in Ho Chi Minh City, Vietnam: [Thesis on the Internet]. University of UPPSALA, 2013. Last accessed August 2016. Available from: http:// www. diva-portal. org/ smash/ get/ diva 2:686782/ FULLTEXT01.pdf

12. Bijoy CV, Feba B, Vilkas RC, Dhaandapani C, Geetha K, \& Vikayakumar A. (2012): Knowledge assessment and patient counseling on diabetic foot care. Indian Journal of Pharmacy Practice 5(2), 11-15.

13. Goodridge D, Trepman E, Embil JM. (2005). Health - related quality of life in diabetic patients with foot ulcers. The Wound, Ostomy and Continence Nurses Society, 42(1) $368-376$.

14. Viswanathan V, Shobhana R, Snehalatha C, Seena R, Ramachandran A. (1999): Need for education on foot care in diabetic patients in India. $\mathbf{J}$ Assoc Physicians India 1999; 47:1083- 5

15. Desalu OO, Salawu FK, Jimoh AK, Adekoya AO, Busari OA and Olokoba AB. (2011). Diabetic Foot Care: Self-Reported Knowledge and Practice Among Patients Attending Three Tertiary Hospitals in Nigeria. GHANA MED J; 45(2):60-65 
Table (1): Distribution of Socio-demographic features and foot care knowledge grade among the studied population.

\begin{tabular}{|c|c|c|c|}
\hline \multicolumn{2}{|l|}{ Variable } & \multirow{2}{*}{$\begin{array}{l}\text { Number } \\
4\end{array}$} & $\%$ \\
\hline \multirow{5}{*}{ Marital status } & Single & & 2.9 \\
\hline & Married & 90 & 64.3 \\
\hline & Separated & 1 & 0.7 \\
\hline & Divorced & 5 & 3.6 \\
\hline & Widowed & 40 & 28.6 \\
\hline \multirow{5}{*}{ Education } & Illiterate & 71 & 50.7 \\
\hline & Primary school & 34 & 24.3 \\
\hline & Preparatory school & 9 & 6.4 \\
\hline & \begin{tabular}{|l|} 
High school \\
\end{tabular} & 13 & 9.3 \\
\hline & \begin{tabular}{|l|} 
Collage \\
\end{tabular} & 13 & 9.3 \\
\hline \multirow{5}{*}{ Occupation } & Laborer & 23 & 16.4 \\
\hline & Government officer & 8 & 5.7 \\
\hline & Technician & 1 & 0.7 \\
\hline & Merchant & 6 & 4.3 \\
\hline & Housewives & 102 & 72.9 \\
\hline \multirow{5}{*}{$\begin{array}{l}\text { Monthly } \\
\text { income }\end{array}$} & Enough & 30 & 21.4 \\
\hline & Barely enough & 49 & 35.0 \\
\hline & Totally inadequate & 61 & 43.6 \\
\hline & Median & \multicolumn{2}{|c|}{650} \\
\hline & Interquartile Range & \multicolumn{2}{|c|}{787.5} \\
\hline \multirow{3}{*}{ Knowledge grade } & poor & 87 & $62.1 \%$ \\
\hline & satisfactory & 34 & $24.3 \%$ \\
\hline & good & 19 & $13.6 \%$ \\
\hline
\end{tabular}

Table (2): Distribution of foot care knowledge score among the three Family Medicine Centers

\begin{tabular}{|l|l|c|c|c|}
\hline \multirow{4}{*}{$\begin{array}{l}\text { Knowledge } \\
\text { score }\end{array}$} & \multicolumn{1}{|c|}{ Centers } & N & Mean \pm SD & Sig. \\
\cline { 2 - 4 } & El - Sadis & 40 & $\mathbf{7 . 1 8} \pm \mathbf{2 . 6 9 7}$ & \multirow{2}{*}{$\mathbf{2 . 1 4 7}$} \\
\cline { 2 - 4 } & El - Darrasa & 50 & $\mathbf{6 . 9 2} \pm \mathbf{3 . 1 6 8}$ & \\
\cline { 2 - 4 } & Saraya & 50 & $\mathbf{5 . 9 6} \pm \mathbf{3 . 0 3 7}$ & $\mathbf{P}=\mathbf{0 . 1 2 1}$ \\
\cline { 2 - 5 } & Total & 140 & $\mathbf{6 . 6 5} \pm \mathbf{3 . 0 1 8}$ & \\
\hline
\end{tabular}


Table (3): Distribution of Foot care knowledge items among the studied population

\begin{tabular}{|c|c|c|}
\hline Knowledge items & Number & $\%$ \\
\hline Importance of taking the treatment to avoid complications & 127 & 90.7 \\
\hline Daily washing the feet & 133 & 95.0 \\
\hline Using warm water for washing/bathing & 70 & 50.0 \\
\hline Checking temperature of water before using & 74 & 52.9 \\
\hline Drying the feet after washing & 60 & 42.9 \\
\hline Talcum powder usage for keeping inter-digital spaces dry & 6 & 4.3 \\
\hline Keeping skin of the feet soft to prevent dryness & 36 & 25.7 \\
\hline Lotion not to be applied to the inter-digital spaces & 10 & 7.1 \\
\hline Daily changes of socks & 60 & 42.9 \\
\hline Trimming nails of feet straight with care & 22 & 15.7 \\
\hline Inspection of feet once a day by yourself & 39 & 27.9 \\
\hline Wearing comfortable coat shoes & 62 & 44.3 \\
\hline Checking the shoes from inside before wearing & 82 & 58.6 \\
\hline Not walking bare foot & 72 & 51.4 \\
\hline Warning signs for which consultation is required & 80 & 57.1 \\
\hline
\end{tabular}


Table (4): Relation between knowledge grade and income of the studied population

\begin{tabular}{|c|c|c|c|c|}
\hline \multirow{2}{*}{\multicolumn{2}{|c|}{ Variable }} & \multirow{2}{*}{$\mathbf{N}$} & Income $(\text { L.E })^{*}$ & \multirow[b]{2}{*}{ Sig. } \\
\hline & & & Mean \pm SD & \\
\hline \multirow{4}{*}{$\begin{array}{l}\text { Knowledge } \\
\text { Grade }\end{array}$} & Poor & 87 & $750.06 \pm 493.864$ & \multirow{4}{*}{$\begin{array}{l}F=6.442 \\
P=.002 *\end{array}$} \\
\hline & Satisfactory & 34 & $1060.29 \pm 551.689$ & \\
\hline & Good & 19 & $1151.58 \pm 790.649$ & \\
\hline & Total & 140 & $879.89 \pm 576.814$ & \\
\hline
\end{tabular}

*L.E= Egyptian pound.

Table (5): Relation between knowledge grade and disease duration

\begin{tabular}{|l|l|c|c|c|}
\hline \multicolumn{2}{|c|}{ Variable } & & Disease duration & \\
\cline { 3 - 4 } & N & Mean \pm SD & \multirow{2}{*}{ Sig. } \\
\hline \multirow{2}{*}{ Knowledge grade } & Poor & 87 & $8.09 \pm 6.606$ & \\
\cline { 2 - 4 } & Satisfactory & 34 & $11.12 \pm 7.040$ & $\begin{array}{l}\text { F= 4.075 } \\
\text { P= .019* }\end{array}$ \\
\cline { 2 - 4 } & Good & 19 & $11.89 \pm 6.582$ & \\
\cline { 2 - 4 } & Total & 140 & $9.34 \pm 6.857$ & \\
\hline
\end{tabular}


Table (6): Relation between Knowledge Grade and Socio-Demographic Features of The Studied Population.

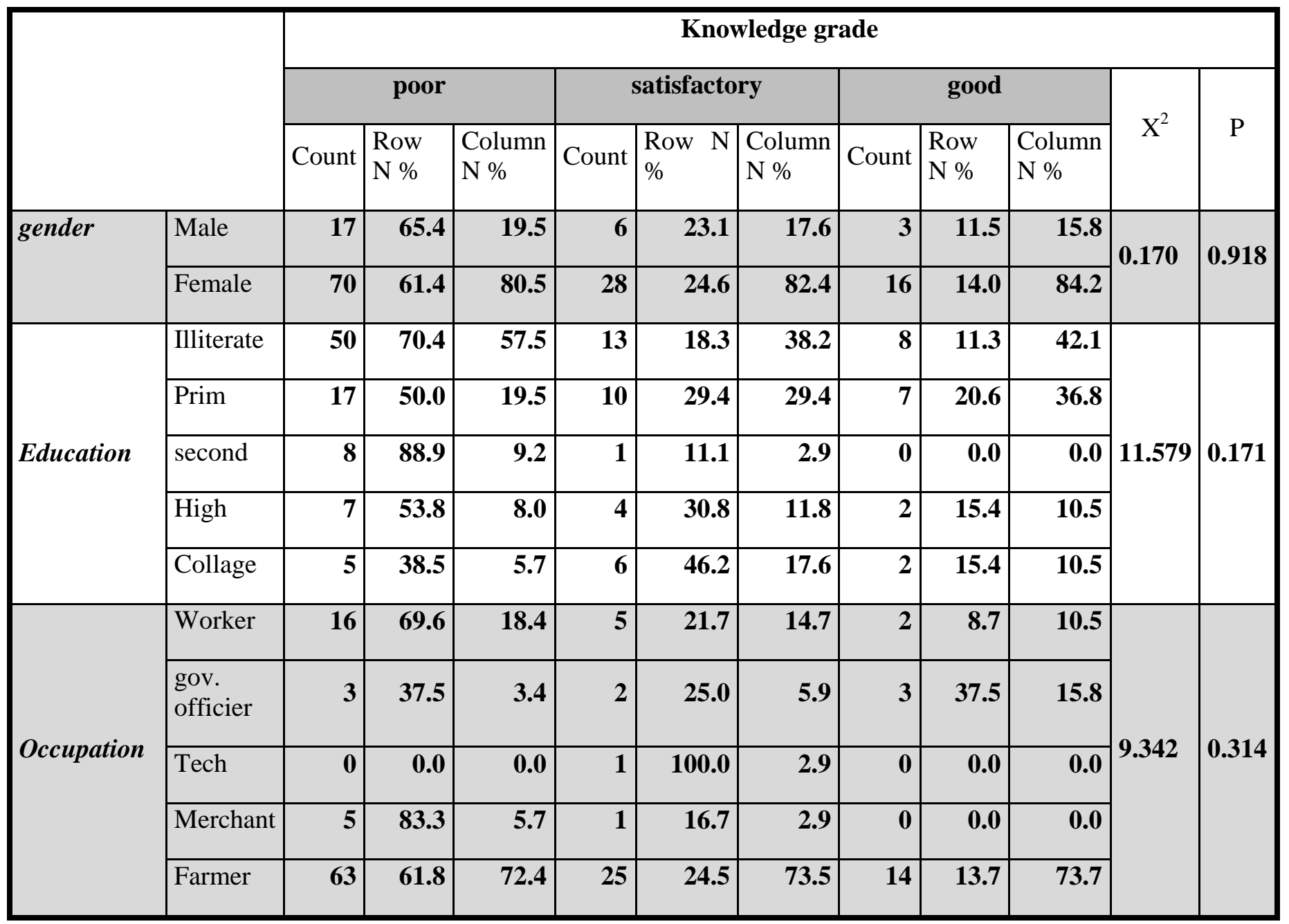


Table (7): Foot Care Education among The Studied Population

\begin{tabular}{|c|c|c|}
\hline Variable & Number & $\%$ \\
\hline Attending a class on how to care for the feet & 11 & 7.9 \\
\hline Reading any handout on foot care & 4 & 2.9 \\
\hline Interest in having a handout on foot care & 128 & 91.4 \\
\hline $\begin{array}{l}\text { The most effective way for increasing foot care knowledge and practice: } \\
\text { - Handouts/Brochures } \\
\text { - Health education group } \\
\text { - Individual health education } \\
\text { - Media e.g. Television, Internet, etc. }\end{array}$ & $\begin{array}{c}6 \\
9 \\
103 \\
22\end{array}$ & $\begin{array}{r}4.3 \\
6.4 \\
73.6 \\
15.7\end{array}$ \\
\hline
\end{tabular}

